\title{
(2) OPEN ACCESS \\ EULAR recommendations for the management of psoriatic arthritis with pharmacological therapies: 2019 update
}

\author{
Laure Gossec 지 , ${ }^{1,2}$ Xenofon Baraliakos, ${ }^{3}$ Andreas Kerschbaumer 주 , ${ }^{4}$

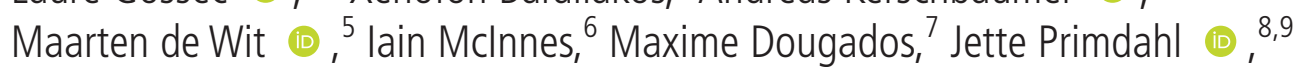 \\ Dennis G McGonagle, ${ }^{10,11}$ Daniel Aletaha, ${ }^{12}$ Andra Balanescu, ${ }^{13}$ Peter V Balint, ${ }^{14}$ \\ Heidi Bertheussen, ${ }^{15}$ Wolf-Henning Boehncke, ${ }^{16}$ Gerd R Burmester, ${ }_{1}^{17}$ \\ Juan D Canete (10, ${ }^{18}$ Nemanja S Damjanov, ${ }^{19}$ Tue Wenzel Kragstrup, ${ }^{20,21}$ \\ Tore K Kvien, ${ }^{22}$ Robert B M Landewé, ${ }^{23,24}$ Rik Jozef Urbain Lories, ${ }^{25,26}$ \\ Helena Marzo-Ortega, ${ }^{10,11}$ Denis Poddubnyy (i), ${ }^{27,28}$

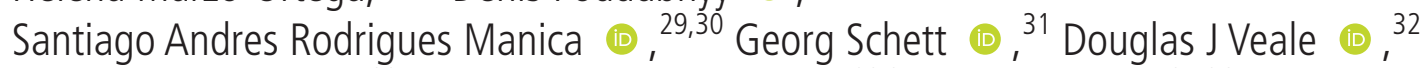 \\ Filip E Van den Bosch, ${ }^{33}$ Désirée van der Heijde (1) ,22,34 Josef S Smolen ${ }^{35,36}$
}

\section{Handling editor David S Pisetsky \\ For numbered affiliations see end of article.}

\section{Correspondence to}

Professor Laure Gossec, Institut Pierre Louis d'Epidémiologie et de Santé Publique, INSERM, Sorbonne Universite, Paris 75013, France;

laure.gossec@gmail.com

Received 13 February 2020 Revised 30 April 2020 Accepted 1 May 2020

\section{Check for updates}

(C) Author(s) (or their employer(s)) 2020. Re-use permitted under CC BY-NC. No commercial re-use. See rights and permissions. Published by BMJ.

\section{To cite: Gossec $L$,}

Baraliakos $X$

Kerschbaumer $A$,

et al. Ann Rheum Dis

2020:79:700-712.

\section{ABSTRACT}

Objective To update the European League Against Rheumatism (EULAR) recommendations for the pharmacological treatment of psoriatic arthritis (PsA). Methods According to the EULAR standardised operating procedures, a systematic literature review was followed by a consensus meeting to develop this update involving 28 international taskforce members in May 2019. Levels of evidence and strengths of recommendations were determined.

Results The updated recommendations comprise 6 overarching principles and 12 recommendations. The overarching principles address the nature of PsA and diversity of both musculoskeletal and non-musculoskeletal manifestations; the need for collaborative management and shared decision-making is highlighted. The recommendations provide a treatment strategy for pharmacological therapies. Non-steroidal anti-inflammatory drugs and local glucocorticoid injections are proposed as initial therapy; for patients with arthritis and poor prognostic factors, such as polyarthritis or monoarthritis/oligoarthritis accompanied by factors such as dactylitis or joint damage, rapid initiation of conventional synthetic disease-modifying antirheumatic drugs is recommended. If the treatment target is not achieved with this strategy, a biological disease-modifying antirheumatic drugs (bDMARDs) targeting tumour necrosis factor (TNF), interleukin (IL)-17A or IL-12/23 should be initiated, taking into account skin involvement if relevant. If axial disease predominates, a TNF inhibitor or IL-17A inhibitor should be started as first-line disease-modifying antirheumatic drug. Use of Janus kinase inhibitors is addressed primarily after bDMARD failure. Phosphodiesterase-4 inhibition is proposed for patients in whom these other drugs are inappropriate, generally in the context of mild disease. Drug switches and tapering in sustained remission are addressed.

Conclusion These recommendations provide stakeholders with an updated consensus on the pharmacological management of PsA, based on a combination of evidence and expert opinion.

\section{INTRODUCTION}

Psoriatic arthritis (PsA) is a disease with heterogeneous manifestations in patients who have manifest or latent psoriasis. It comprises both musculoskeletal as well as non-musculoskeletal manifestations; the latter particularly include the skin and the nails, but also potentially the gut (inflammatory bowel disease) or the eyes (uveitis). Active chronic PsA also associates with cardiovascular, psychological and metabolic comorbidities, ${ }^{1-7}$ which, together with the musculoskeletal manifestations, impose a significant patient burden with impact on quality of life and also accelerated mortality. ${ }^{8-10}$

The day-to-day management of patients with PsA includes non-pharmacological as well as pharmacological interventions. The number of disease-modifying antirheumatic drugs (DMARDs) indicated for PsA has increased during the last decade. The armamentarium now includes not only conventional synthetic DMARDs (csDMARDs) such as methotrexate (MTX), sulfasalazine and leflunomide and tumour necrosis factor inhibitors (TNFi), but also other targeted biological agents (bDMARDs) aimed at different cytokines, such as TNF, interleukin (IL)-12/23 and IL-17A, as well as targeted synthetic DMARDs (tsDMARDs) that inhibit phosphodiesterase-4 (PDE4) or Janus kinases (JAKs). ${ }^{11-16}$ These multiple newer drugs have been investigated well in short-term, randomised controlled trials using placebo as comparator for reasons of drug approval. However, comparative research of different drugs, important for clinical practice, is rather sparse and clinicians need some guidance in decision-making. ${ }^{17-20}$

The European League Against Rheumatism (EULAR) developed recommendations for the pharmacological management of PsA in 2011 and updated them in 2015. These recommendations had their main focus on the musculoskeletal aspects of the disease and addressed the entire spectrum of PsA severity since they pertained to patients with very mild to very severe PsA. ${ }^{12} 15$ In this rapidly 
evolving field, a further update of the 2015 recommendations became necessary to accommodate newly obtained evidence and insights. The objective of this taskforce, therefore, was to update the EULAR recommendations for the management of PsA with non-topical, pharmacological therapies.

\section{METHODS}

The updated EULAR standardised operating procedures were applied. ${ }^{21}$ In October 2018, a steering group consisting of five rheumatologists, a fellow, a patient research partner and a health professional defined the questions that were to be addressed through a systematic literature review (SLR). The SLR was performed between October 2018 and May 2019, for the years 2015-2018, and analysed the efficacy in both musculoskeletal manifestations as well as the skin and nails in patients with PsA. ${ }^{1}$ Of note, the SLR was not centred on skin psoriasis trials, and these trials are not reviewed systematically or alluded to systematically here. Where relevant and based on expert opinion, data made available after the end of the SLR were also integrated. In May 2019, the steering group as well as the taskforce met to integrate available information on disease management in PsA into practical recommendations. The taskforce consisted of 28 persons from 15 European countries with 15 different healthcare systems: 21 rheumatologists, 2 people affected with PsA, 1 health professional, 1 dermatologist and 3 rheumatology fellows/trainees. The taskforce comprised more than 30\% new members compared with 2015.

The SLR informed the recommendations. However, the process was not only evidence-based but also experience-based and consensus-based, in line with the three-tier principles of evidence-based medicine that include clinical science (trials), patients' perceptions and expectations, and physicians' experiences. Benefit to cost ratios were taken into consideration when discussing prioritisation of drugs, since new effective treatments impose a significant burden on the healthcare budgets of EULAR and non-EULAR countries. Treatment guidance should therefore not only include considerations about safety and efficacy but should also focus on cost of treatment, in particular when different therapies have similar efficacy and safety data.

The results of the SLR were presented to the taskforce during a face-to-face meeting in May 2019, alongside the 2015 recommendations and proposals for changes to these recommendations prepared by the steering committee. Each recommendation was discussed in detail both in smaller (breakout) groups and in plenary sessions until consensus was reached. For changes to existing recommendations against which no new evidence has accrued since the last update, a $\geq 75 \%$ vote by the taskforce was mandated in order to prevent new taskforces from reformulating without major reasoning what had previously been developed based on the evidence presented at that point in time. If this majority was not reached, the recommendation was not changed. New recommendations were formulated and then accepted if $\geq 75 \%$ of the members agreed; if this agreement was not reached, the recommendation was reworded and subjected to a renewed vote for which a $\geq 67 \%$ majority was required. If this was not achieved, the wording underwent a next round of discussion and the new phrasing was approved if $>50 \%$ of the taskforce members voted for it.

After the face-to-face meeting, the taskforce members were provided with the category of evidence and grade of recommendation for each item, based on the Oxford Evidence Based Medicine categorisation, as per the EULAR procedures. ${ }^{21}{ }^{22}$ Then an anonymised, email-based voting on the level of agreement among the taskforce members was performed on a $0-10$ scale (with 10 meaning full agreement) allowing calculation of mean levels of agreement.

\section{RESULTS}

The recommendations are shown in table 1 , and the modifications compared with the previous recommendations are shown in table 2. These recommendations address non-topical pharmacological treatments with a main focus on musculoskeletal manifestations. As before, the updated recommendations are targeted at various stakeholders, such as (1) experts involved in the care of patients with PsA, particularly rheumatologists and other health professionals (such as rheumatology nurses), but also general practitioners, dermatologists and other specialists; (2) people with PsA who can use these recommendations for information on current therapies, treatment strategies and opportunities; and (3) other stakeholders which include government and hospital officials, patient organisations, regulatory agencies and reimbursement institutions.

\section{Overarching principles}

These refer to principles of a generic nature (table 1). Note that optimal management of patients with PsA also requires non-pharmacological strategies such as patient education and regular physical exercise and may also require topical medication (in particular for skin psoriasis). The non-systemic and non-pharmacological therapies are not addressed in the present document. ${ }^{23}$

The overarching principles remained mostly unchanged compared with 2015 (table 2). Principle A refers to the heterogeneous and potentially severe nature of PsA, and principle B addresses the importance of shared decision-making with the patient, but also costs. Indeed, while efficacy and safety are considered to be the key drivers of the decision-making process, the committee noted that cost of treatment should also be taken into account. Modern DMARDs are expensive and unaffordable to many patients in less-affluent countries, but also in affluent countries social security systems may preclude provision of certain drugs to a significant proportion of patients, or request clinically unacceptable conditions (such as high disease activity or limitation of important agents to a maximum number) for cost reasons. Nevertheless, EULAR proclaims that all patients with active and/or severe (not necessarily highly active) PsA should have the right to be prescribed the treatment they need to optimise their quality of life. Of note, recently, costs of some drugs have decreased considerably through access to biosimilars and bio-originator repricing, but these advantages are not conveyed in all countries alike.

The pivotal status of the rheumatologist as the main caregiver for people with PsA is dealt with in principle C. Rheumatologists possess the optimal depth and breadth of experience regarding the use of all types of DMARDs, including efficacy outcomes, risk assessment and knowledge of comorbidities. The role of nurses and other health professionals in the management of PsA, in relation to principles $\mathrm{A}$ and $\mathrm{B}$, was addressed by the taskforce. While rheumatologists are the principal physicians in the care of PsA, in some countries rheumatology nurses may prescribe medication and are the main healthcare givers for patients. On the other hand, in certain areas of the world, rheumatology training is not sufficiently available and other experts may care for patients with PsA, hence the term 'primarily'. Where there is a lack of rheumatologists, the taskforce recognised the contribution of other physicians with appropriate rheumatological 
Table 12019 EULAR recommendations for the pharmacological management of psoriatic arthritis, with levels of evidence, grade of recommendations and level of agreement

\section{Overarching principles}

A Psoriatic arthritis is a heterogeneous and potentially severe disease, which may require multidisciplinary treatment.

B Treatment of psoriatic arthritis patients should aim at the best care and must be based on a shared decision between the patient and the rheumatologist, considering efficacy, safety and costs.

C Rheumatologists are the specialists who should primarily care for the musculoskeletal manifestations of patients with psoriatic arthritis; in the presence of clinically significant skin involvement, a rheumatologist and a dermatologist should collaborate in diagnosis and management.

D The primary goal of treating patients with psoriatic arthritis is to maximise health-related quality of life, through control of symptoms, prevention of structural damage, normalisation of function and social participation; abrogation of inflammation is an important component to achieve these goals.

E In managing patients with psoriatic arthritis, consideration should be given to each musculoskeletal manifestation and treatment decisions made accordingly.

F When managing patients with psoriatic arthritis, non-musculoskeletal manifestations (skin, eye and gastrointestinal tract) should be taken into account; comorbidities such as metabolic syndrome, cardiovascular disease or depression should also be considered.

Level of agreement mean (SD)

$9.9(0.4)$

$9.8(0.5)$

$9.8(0.7)$

$9.9(0.4)$

$9.9(0.3)$

$9.8(0.6)$

\section{Recommendations}

Level of

Grade of

Level of agreement,

evidence

recommendation

1 Treatment should be aimed at reaching the target of remission or, alternatively, low disease activity, by regular 1 disease activity assessment and appropriate adjustment of therapy.

2 Non-steroidal anti-inflammatory drugs may be used to relieve musculoskeletal signs and symptoms.

1b $\quad A$

A

$9.4(1.0)$

Local injections of glucocorticoids should be considered as adjunctive therapy in psoriatic arthritis*; systemic glucocorticoids may be used with caution at the lowest effective doset.

4 In patients with polyarthritis, a csDMARD should be initiated* rapidlyt, with methotrexate preferred in those with relevant skin involvement*.

5 In patients with monoarthritis or oligoarthritis, particularly with poor prognostic factors such as structural damage, high erythrocyte sedimentation rate/C reactive protein, dactylitis or nail involvement, a csDMARD should be considered.

6 In patients with peripheral arthritis and an inadequate response to at least one CSDMARD, therapy with a bDMARD should be commenced; when there is relevant skin involvement, an IL-17 inhibitor or IL-12/23 inhibitor may be preferred.

7 In patients with peripheral arthritis and an inadequate response to at least one cSDMARD and at least one bDMARD, or when a bDMARD is not appropriate, a JAK inhibitor may be considered.

8 In patients with mild disease* and an inadequate response to at least one csDMARDt, in whom neither a bDMARD nor a JAK inhibitor is appropriate*, a PDE4 inhibitor may be considered.

9 In patients with unequivocal enthesitis and insufficient response to NSAIDs or local glucocorticoid injections, therapy with a bDMARD should be considered

10 In patients with predominantly axial disease which is active and has insufficient response to NSAIDs, therapy with a bDMARD should be considered, which according to current practice is a TNF inhibitor; when there is relevant skin involvement, IL-17 inhibitor may be preferred.

11 In patients who fail to respond adequately to, or are intolerant of a bDMARD, switching to another bDMARD or 1b tsDMARD should be considered*, including one switch within a classt.

12 In patients in sustained remission, cautious tapering of DMARDs may be considered.

$\begin{array}{lll}1 \mathrm{~b} & \mathrm{~A} & 9.6(0.8) \\ 3 \mathrm{~b}^{*} & \mathrm{C} & 9.5(1.1) \\ 4 \dagger & & 9.5(0.8) \\ 1 \mathrm{~b}^{*} & \mathrm{~B} & 9.3(1.0) \\ 5 \dagger & & \\ 4 & \mathrm{C} & 9.4(1.1)\end{array}$

$\begin{array}{lll}\text { 1b } & \text { B } & 9.2(1.3) \\ 5^{*} & B & 8.5(1.9) \\ 1 \mathrm{~b} \dagger & & 9.3(0.9) \\ 1 \mathrm{~b} & \mathrm{~B} & 9.7(0.6) \\ \mathrm{1b} & \mathrm{B} & \end{array}$

The level of agreement was computed on a $0-10$ scale.

cSDMARDs include methotrexate, sulfasalazine or leflunomide; bDMARDs include here TNF inhibitors (both original and biosimilars) and drugs targeting the IL-17 and IL-12/23 pathways.

bDMARDs, biological disease-modifying antirheumatic drugs; csDMARDs, conventional synthetic disease-modifying antirheumatic drugs; DMARDs, disease-modifying antirheumatic drugs; EULAR, European League Against Rheumatism; IL, interleukin; JAK, Janus kinase; NSAIDs, non-steroidal anti-inflammatory drugs; PDE4,

phosphodiesterase-4; TNF, tumour necrosis factor.

expertise and added this point also into the research agenda (table 3).

The treatment target is elimination of inflammation and optimisation of quality of life (principle D) (see table 1 and the 2015 update for detailed information). ${ }^{18}$ The importance of fatigue was also highlighted. ${ }^{1571024}$

The last two overarching principles refer to treatment strategy and have been modified. Principle E is a new overarching principle which reiterates the importance of all musculoskeletal manifestations in patients with PsA: this not only relates to peripheral arthritis but also enthesitis, tenosynovitis, tendinitis, dactylitis and inflammatory axial disease.

Principle F (which in 2015 was principle E) now includes the term 'non-musculoskeletal', replacing the term 'extra-articular' manifestations, and refers to PsA-linked organ involvement, namely psoriasis, uveitis and inflammatory bowel disease. The term 'extra-articular manifestations' was considered unclear-for some it includes axial or entheseal symptoms, which was not intended in this context. ${ }^{25-27}$ Although all the non-musculoskeletal manifestations should be taken into account, psoriasis is of course the most frequent. Referring to comorbidities, aside from cardiovascular disease, depression is explicitly mentioned because of its frequency and impact on the patient. ${ }^{4710242829}$ The list of comorbidities is not meant to be exhaustive and other comorbidities should also be considered.

\section{Recommendations}

Twelve recommendations were formulated or updated (tables 1 and 2) and formed the basis of the management algorithm (figure 1). Table 1 provides the category of evidence, grade of recommendation and level of agreement for each of the points. ${ }^{17}$ It must be borne in mind that the individual disease characteristics - in line with the multidimensional nature of PsA-may 
Table 2 Comparison of the 2015 and 2019 recommendations

\begin{tabular}{|c|c|c|c|}
\hline \multicolumn{2}{|c|}{2019 (current) version } & Changes performed & 2015 version \\
\hline \multicolumn{4}{|c|}{ Overarching principles } \\
\hline A & $\begin{array}{l}\text { Psoriatic arthritis is a heterogeneous and potentially severe disease, which may } \\
\text { require multidisciplinary treatment. }\end{array}$ & Unchanged & $\begin{array}{l}\text { Psoriatic arthritis is a heterogeneous and potentially severe disease, which may requir } \\
\text { multidisciplinary treatment. }\end{array}$ \\
\hline B & $\begin{array}{l}\text { Treatment of psoriatic arthritis patients should aim at the best care and must } \\
\text { be based on a shared decision between the patient and the rheumatologist, } \\
\text { considering efficacy, safety and costs. }\end{array}$ & Unchanged & $\begin{array}{l}\text { Treatment of psoriatic arthritis patients should aim at the best care and must be basec } \\
\text { on a shared decision between the patient and the rheumatologist, considering efficac, } \\
\text { safety and costs. }\end{array}$ \\
\hline C & $\begin{array}{l}\text { Rheumatologists are the specialists who should primarily care for the } \\
\text { musculoskeletal manifestations of patients with psoriatic arthritis; in the presence } \\
\text { of clinically significant skin involvement, a rheumatologist and a dermatologist } \\
\text { should collaborate in diagnosis and management. }\end{array}$ & Unchanged & $\begin{array}{l}\text { Rheumatologists are the specialists who should primarily care for the musculoskeletal } \\
\text { manifestations of patients with psoriatic arthritis; in the presence of clinically significa } \\
\text { skin involvement, a rheumatologist and a dermatologist should collaborate in diagnos } \\
\text { and management. }\end{array}$ \\
\hline D & $\begin{array}{l}\text { The primary goal of treating patients with psoriatic arthritis is to maximise health- } \\
\text { related quality of life, through control of symptoms, prevention of structural } \\
\text { damage, normalisation of function and social participation; abrogation of } \\
\text { inflammation is an important component to achieve these goals. }\end{array}$ & Unchanged & $\begin{array}{l}\text { The primary goal of treating patients with psoriatic arthritis is to maximise health- } \\
\text { related quality of life, through control of symptoms, prevention of structural damage, } \\
\text { normalisation of function and social participation; abrogation of inflammation is an } \\
\text { important component to achieve these goals. }\end{array}$ \\
\hline$E$ & $\begin{array}{l}\text { In managing patients with psoriatic arthritis, consideration should be given to each } \\
\text { musculoskeletal manifestation and treatment decisions made accordingly. }\end{array}$ & New & Not applicable. \\
\hline $\mathrm{F}$ & $\begin{array}{l}\text { When managing patients with psoriatic arthritis, non-musculoskeletal } \\
\text { manifestations (skin, eye and gastrointestinal tract) should be taken into account; } \\
\text { comorbidities such as metabolic syndrome, cardiovascular disease or depression }\end{array}$ & Rephrased & $\begin{array}{l}\text { When managing patients with psoriatic arthritis, extra-articular manifestations, } \\
\text { metabolic syndrome, cardiovascular disease and other comorbidities should be taken } \\
\text { into account. }\end{array}$ \\
\hline
\end{tabular}

Recommendations

1 Treatment should be aimed at reaching the target of remission or, alternatively, low Rephrased disease activity, by regular disease activity assessment and appropriate adjustment of therapy.

2 Non-steroidal anti-inflammatory drugs may be used to relieve musculoskeletal Rephrased signs and symptoms.

3 Local injections of glucocorticoids should be considered as adjunctive therapy in Renumbered psoriatic arthritis; systemic glucocorticoids may be used with caution at the lowest effective dose.

4 In patients with polyarthritis, a csDMARD should be initiated rapidly, with Modified methotrexate preferred in those with relevant skin involvement.

5 In patients with monoarthritis or oligoarthritis, particularly with poor prognostic factors such as structural damage, high erythrocyte sedimentation rate/C reactive protein, dactylitis or nail involvement, a csDMARD should be considered.

6 In patients with peripheral arthritis and an inadequate response to at least one CSDMARD, therapy with a bDMARD should be commenced; when there is relevant skin involvement, an IL-17 inhibitor or IL-12/23 inhibitor may be preferred. minimal/low disease activity, by regular monitoring and appropriate adjustment of therapy.

In patients with psoriatic arthritis, non-steroidal anti-inflammatory drugs may be used to relieve musculoskeletal signs and symptoms.

Local injections of glucocorticoids should be considered as adjunctive therapy in psoriatic arthritis; systemic glucocorticoids may be used with caution at the lowest effective dose.

In patients with peripheral arthritis, particularly in those with many swollen joints, structural damage in the presence of inflammation, high ESR/CRP and/or clinically relevant extra-articular manifestations, csDMARDs should be considered at an early stage, with methotrexate preferred in those with relevant skin involvement. Not applicable but partly covered in the recommendation above.

7 In patients with peripheral arthritis and an inadequate response to at least one csDMARD and at least one bDMARD, or when a bDMARD is not appropriate, a JAK inhibitor may be considered.

8 In patients with mild disease and an inadequate response to at least one cSDMARD, Modified in whom neither a bDMARD nor a JAK inhibitor is appropriate, a PDE4 inhibitor may be considered.

9 In patients with unequivocal enthesitis and insufficient response to NSAIDs or local Modified glucocorticoid injections, therapy with a bDMARD should be considered.

10 In patients with predominantly axial disease which is active and has insufficient Modified response to NSAIDs, therapy with a bDMARD should be considered, which according to current practice is a TNF inhibitor; when there is relevant skin involvement, IL-17 inhibitor may be preferred.

11 In patients who fail to respond adequately to, or are intolerant of a bDMARD, switching to another bDMARD or tsDMARD should be considered*, including one switch within a classt.

12 In patients in sustained remission, cautious tapering of DMARDs may be considered.

\section{New \\ Not applicable.}

Modified

New

Not applicable
In patients with peripheral arthritis and an inadequate response to at least one csDMARD, therapy with a bDMARD, usually a TNF inhibitor, should be commenced. In patients with peripheral arthritis and an inadequate response to at least one csDMARD, in whom TNF inhibitors are not appropriate, bDMARDs targeting IL-12/23 or IL-17 pathways may be considered.

In patients with peripheral arthritis and an inadequate response to at least one csDMARD, in whom bDMARDs are not appropriate, a targeted synthetic DMARD such as a PDE4 inhibitor may be considered.

In patients with active enthesitis and/or dactylitis and insufficient response to NSAIDs or local glucocorticoid injections, therapy with a bDMARD should be considered, which according to current practice is a TNF inhibitor.

In patients with predominantly axial disease that is active and has insufficient response to NSAIDs, therapy with a bDMARD should be considered, which according to current practice is a TNF inhibitor.

In patients who fail to respond adequately to a bDMARD, switching to another bDMARD should be considered, including switching between TNF inhibitors.

cSDMARDs include methotrexate, sulfasazine or leflunomide; bDMARDs include here TNF inhibitors (both original and biosimilars) and drugs targeting the IL-17 and IL-12/23 pathways.

bDMARDs, biological disease-modifying antirheumatic drugs; CRP, C reactive protein; csDMARDs, conventional synthetic disease-modifying antirheumatic drugs; DMARDs, disease-modifying antirheumatic drugs; ESR, erythrocyte sedimentation rate; IL, interleukin; JAK, Janus kinase; NSAIDs, non-steroidal anti-inflammatory drugs; PDE4, phosphodiesterase-4; TNF, tumour necrosis factor; tsDMARDs, targeted synthetic diseasemodifying antirheumatic drugs.

respond differently to specific therapies and thus require use of distinct assessment instruments for each manifestation. This variability as well as contraindications and risks must be taken into account, and thus the balance between efficacy and safety is always dependent on the characteristics of the individual patient. Both table 1 and figure 1 synthesise the recommendations in an abbreviated way, and the accompanying text provides more detailed information about the evidence and the discussion process and should be regarded as integral to the recommendations.

Recommendation 1: Treatment should be aimed at reaching the target of remission or, alternatively, low disease activity, by regular disease activity assessment and appropriate adjustment of therapy. This recommendation puts forward the importance of a treatto-target (T2T) approach. The T2T strategy, which comprises 


\section{Table 3 Research agenda for PsA}

\begin{tabular}{|c|c|}
\hline Theme & Research questions \\
\hline Responsibility & Role of the rheumatologist vs other specialists in the management of PsA. \\
\hline Diagnosis & $\begin{array}{l}\text { Defining screening strategies for PsA among patients with psoriasis: is screening needed, and if so in which populations, how and when? } \\
\text { Criteria for early diagnosis of PsA, including predictors for the development of PsA in patients with skin psoriasis. } \\
\text { Diagnosis of axial involvement. }\end{array}$ \\
\hline Prognosis & $\begin{array}{l}\text { Defining prognostic factors related to risk of progressive disease, structural damage and bad functional outcome in early (and established) PsA. } \\
\text { Predicting response to treatment (predicting response to NSAIDs, to csDMARDs, to the different bDMARDs, to tsDMARDs). } \\
\text { Assessment of spinal disease: defining the similarities and differences with spondyloarthritis. }\end{array}$ \\
\hline Pathophysiology & $\begin{array}{l}\text { Defining the relationship between inflammation and structural damage in PsA. } \\
\text { Exploring juvenile PsA: is it different from adult-onset PsA? } \\
\text { Identification of new therapeutic targets. } \\
\text { Pathogenetic pathways leading to arthritis, dactylitis, enthesitis, tenosynovitis, tendinitis, axial disease and skin disease; similarities and differences. } \\
\text { Genetics of PsA. }\end{array}$ \\
\hline Phenotypes & $\begin{array}{l}\text { Entheseal PsA: overlap with widespread pain syndrome and role of imaging in the diagnosis. } \\
\text { Axial PsA: definition and role of imaging in the diagnosis. }\end{array}$ \\
\hline Biomarkers & Determining biomarkers related to early diagnosis, damage, prognosis and treatment response. \\
\hline Treatment strategy & $\begin{array}{l}\text { Assessing efficacy and safety of combinations of csDMARDs compared with csDMARD monotherapy (with and without low-dose glucocorticoids). } \\
\text { Assessing efficacy and safety of combinations of csDMARDs with biologics compared with biologics monotherapy. } \\
\text { Comparing efficacy and safety of methotrexate vs biological monotherapy vs their combination in early PsA. } \\
\text { Evaluating the need for early treatment in PsA: Who should be treated with csDMARDs? When to start treatment with DMARDs? } \\
\text { Switching and cycling between drugs. } \\
\text { Therapeutic drug monitoring to optimise cost and to support switching between bDMARDs within the same class or to a different mode of action. } \\
\text { Efficacy in oligoarticular rather than in polyarticular disease. } \\
\text { Efficacy in axial disease. } \\
\text { Strategy trials. }\end{array}$ \\
\hline Outcomes & $\begin{array}{l}\text { Composite scores in PsA and assessment of treatment outcomes. } \\
\text { Usefulness of separate assessment of multiple scores limited to some specific domains in PsA. } \\
\text { Axial involvement in PsA. } \\
\text { Fatigue in PsA. }\end{array}$ \\
\hline csDMARDs & $\begin{array}{l}\text { Efficacy of methotrexate in PsA, including for enthesitis. } \\
\text { Efficacy of csDMARDs for dactylitis. } \\
\text { Efficacy and safety of combination therapy of csDMARDs. } \\
\text { Strategy of csDMARDs before bDMARDs/tsDMARDs. }\end{array}$ \\
\hline bDMARDs and tsDMARDs & $\begin{array}{l}\text { Efficacy of combining csDMARDs with bDMARDs, compared with bDMARD monotherapy and with cSDMARD monotherapy. } \\
\text { Comparison of apremilast with methotrexate. } \\
\text { Timing to start bDMARDs. } \\
\text { Duration of biological therapy, including addressing bDMARD dose reduction or discontinuation. } \\
\text { Head-to-head trials. } \\
\text { Structural data for apremilast. } \\
\text { How to identify the right bDMARD for the right patient phenotype. } \\
\text { Comparative safety of bDMARDs in PsA. } \\
\text { Differential effects of bDMARDs on comorbidities such as metabolic syndrome. }\end{array}$ \\
\hline Systemic glucocorticoids & $\begin{array}{l}\text { Assessing the risk of skin flares related to systemic glucocorticoids and in particular at low doses. } \\
\text { Assessing the benefit to risk ratio of long-term glucocorticoid therapy. }\end{array}$ \\
\hline Switches & $\begin{array}{l}\text { Strategies after failures of bDMARDs other than TNFi. } \\
\text { Repeat switching within a bDMARD class. }\end{array}$ \\
\hline Comorbidities & $\begin{array}{l}\text { Cardiovascular disease and metabolic syndrome in PsA and links with disease activity. } \\
\text { Alcohol in PsA in particular when treating with methotrexate. } \\
\text { Cardiovascular risk and DMARDs in PsA. }\end{array}$ \\
\hline
\end{tabular}

non-steroidal anti-inflammatory drugs; PsA, psoriatic arthritis; TNFi, tumour necrosis factor inhibitor; tsDMARDs, targeted synthetic disease-modifying antirheumatic drugs.

definition of a distinct target as well as adherence to rules for monitoring and therapeutic adjustment, is well validated particularly in rheumatoid arthritis. ${ }^{30}$ The T2T recommendations for PsA have been updated recently. ${ }^{31} 32$ In line with these recommendations, this point has been slightly rephrased and now states clearly that remission or low disease activity should be targeted, with the deletion of the previously stated term of minimal disease activity (which refers to a score allowing the assessment of low disease activity rather than to a target). ${ }^{33} 34$ Remission in PsA is difficult to define. ${ }^{33}$ Remission should be seen as abrogation of inflammation.

Recommendation 2: Non-steroidal anti-inflammatory drugs may be used to relieve musculoskeletal signs and symptoms.

As in previous versions the taskforce continues to recommend the use of an non-steroidal anti-inflammatory drug (NSAID) to relieve symptoms. ${ }^{18}$ The benefit to risk ratio of NSAIDs must always be considered carefully, especially in this population with frequent cardiovascular comorbidities.

The taskforce noted that, in contrast to rheumatoid arthritis, in mild synovitis in PsA or for non-synovial features including axial symptoms, NSAIDs alone may be sufficient to control symptoms, especially with local glucocorticoid injections (see recommendation 3). There are little data regarding the efficacy of NSAIDs in enthesitis. In patients with peripheral arthritis, NSAIDs should be combined rapidly with DMARDs if needed (see also recommendations 4 and 5). NSAIDs have not shown any efficacy in skin psoriasis. When peripheral arthritis is present, NSAID monotherapy without DMARDs should not exceed 1 month if disease activity persists, and other treatment possibilities should be considered. When axial or entheseal involvement dominates the clinical picture, the duration of NSAID therapy might be prolonged up to 12 weeks, provided they have already induced relief by 4 weeks. ${ }^{35}$ If the treatment target is not achieved, other 


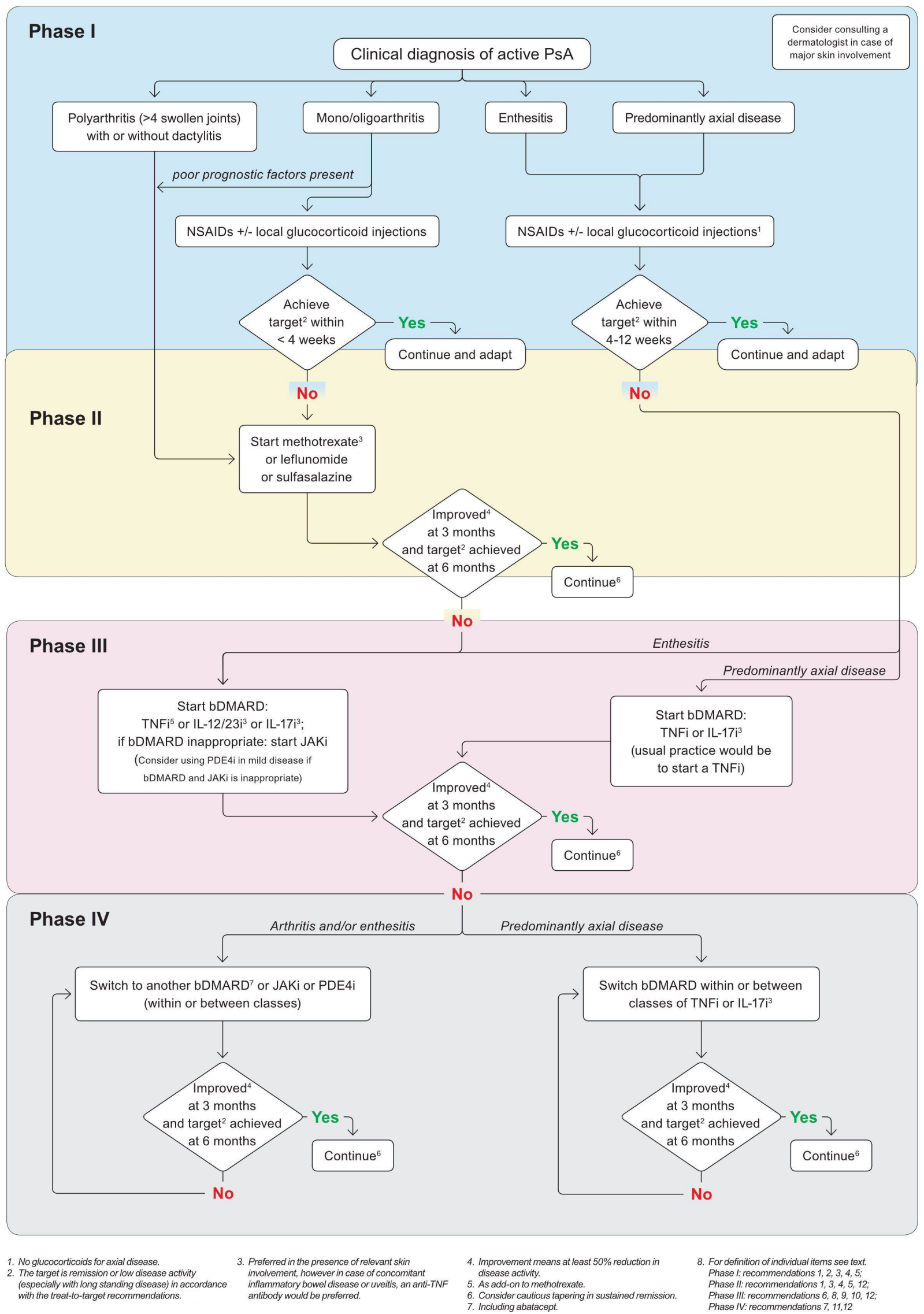

Figure 1 The EULAR 2019 algorithm for treatment of PsA with pharmacological non-topical treatments. bDMARDs, biological disease-modifying antirheumatic drugs; EULAR, European League Against Rheumatism; IL-12/23i, interleukin-12/23 inhibitor; IL-17i, interleukin-17 inhibitor; JAKi, Janus kinase inhibitor; NSAIDs, non-steroidal anti-inflammatory drugs; PDE4i, phosphodiesterase-4 inhibitor; PsA, psoriatic arthritis; TNFi, tumour necrosis factor inhibitor. 
therapies should be prescribed as detailed in the subsequent recommendations.

Recommendation 3: Local injections of glucocorticoids should be considered as adjunctive therapy in psoriatic arthritis; systemic glucocorticoids may be used with caution at the lowest effective dose.

This recommendation is unchanged compared with 2015 but has been reordered to better align with the different phases of treatment (figure 1). ${ }^{18}$ It has to be also noted that glucocorticoid therapy should be used for only a short period of time. The taskforce does not recommend the use of systemic glucocorticoids for axial disease. ${ }^{35}$

Recommendation 4: In patients with polyarthritis, a csDMARD should be initiated rapidly, with methotrexate preferred in those with relevant skin involvement.

The main change in recommendations 4 and 5 (together recommendation 3 in 2015) is the separation of polyarticular versus oligoarticular joint involvement to ensure that the poorer prognostic nature of polyarthritis is more strongly emphasised than this was done before. The taskforce defined polyarticular disease as five or more active (swollen) joints. ${ }^{36}$ Patients with polyarticular disease should receive a csDMARD either as first-line drug or after only a short course of NSAIDs. 'Rapid' infers prompt commencement of a csDMARD, commensurate with the severity of clinical presentation or comorbidities; delays should not exceed 2 weeks. Thus, while recommendation 4 has been newly added, it was already comprised in former recommendation 3, where 'many swollen joints' was mentioned as a poor prognostic marker requiring rapid ('early') institution of DMARDs.

This recommendation, as well as recommendation 5, places the use of csDMARDs in the management of PsA as first-line DMARDs. The continuous prioritisation of csDMARDs reflects consensual expert opinion within the taskforce that favoured the benefit to risk balance of csDMARDs and in particular MTX over biologicals, as well as their lower cost. Data supporting the use of MTX in PsA are scarce and include only small or inconclusive clinical trials, ${ }^{37}$ as well as indirect evidence stemming from the TICOPA trial and evidence from observational studies. ${ }^{38-41}$ However, the SEAM-PsA study, which was part of the SLR and has meanwhile been published in full, revealed that MTX has similar efficacy in joint counts, skin involvement, enthesitis, dactylitis and physical function as etanercept or even etanercept plus MTX. ${ }^{42}$ Given this similarity of effectiveness, and the differences in costs, this study further supports the taskforce's decision to place MTX and other csDMARDs at the top of the therapeutic algorithm (figure 1).

The taskforce acknowledged that patients may have a reluctance to take MTX and may experience adverse effects. To our knowledge, data proving that MTX is less well tolerated in PsA than in rheumatoid arthritis are lacking, but the effects of and the overall long-term experience with MTX should be part of the information given to the patient in the process of shared decision-making. ${ }^{43}$ Thus far, MTX remains widely used in daily practice as reported in registries, has high treatment maintenance over time and seems effective in the control arms of most clinical trials, in which disease control with MTX monotherapy appears satisfactory. ${ }^{42}$

MTX is highlighted among the csDMARDs, in particular for patients with 'relevant' skin involvement: 'relevant' is defined as either extensive (body surface area involvement $>10 \%$ ), or as important to the patient: more limited psoriasis leading to significant impact on quality of life (eg, face/hand/feet/genital involvement). This definition would correspond, in other dermatological terms, to moderate to severe psoriasis. MTX has proven efficacy in skin psoriasis, is recommended in treatment guidelines for psoriasis and has become the standard csDMARD for skin psoriasis in many countries. ${ }^{44-47}$

On the other hand, MTX leads to hepatotoxicity, and data on the beneficial effects of MTX on cardiovascular disease in PsA are conflicting. ${ }^{48} 49$ Taking all these elements into account, the taskforce felt a gradual approach to intensify PsA treatment most appropriate and proposed a csDMARD (usually MTX) as the first DMARD. MTX should be prescribed attempting to reach $25 \mathrm{mg}$ per week as the optimal dose and with folate supplementation. Other csDMARDs have shown efficacy in PsA as well and may also be considered at this stage (although with less efficacy in the skin): these include leflunomide and sulfasalazine. ${ }^{50} \mathrm{Ciclo}-$ sporin is not recommended for PsA.

If improvement does not exceed $50 \%$ of a composite measure for PsA within 3 months or the treatment target is not reached within 6 months, such csDMARD therapy should not be pursued longer (figure 1). In light of paucity of good clinical data, the search for better evidence for the efficacy of csDMARDs as monotherapy or as combination therapy was prioritised on the research agenda.

Recommendation 5: In patients with monoarthritis or oligoarthritis, particularly with poor prognostic factors such as structural damage, high erythrocyte sedimentation rate/C reactive protein, dactylitis or nail involvement, a csDMARD should be considered.

This recommendation emphasises that patients with oligoarticular disease should (similar to polyarticular patients) receive a csDMARD rapidly in the presence of poor prognostic factors (please see the text of the recommendation). Concerning factors associated with poor prognosis (here defined as radiographic severity), the SLR identified nail involvement in addition to those factors presented in 2011 and 2015, and this element was added accordingly to the phrasing of recommendation 5.152

Dactylitis was previously addressed together with enthesitis (see recommendation 9 in 2015). However, these manifestations have now been separated. The taskforce considered that dactylitis was distinct in terms of physiopathology, diagnosis and prognosis, since it is linked to radiographic changes in PsA, whereas enthesitis is not. ${ }^{53}$ Furthermore, although there is a lack of good-quality data, recent studies suggest at least some efficacy of MTX in dactylitis. ${ }^{41} 42$ Thus, dactylitis should now be treated similarly to arthritis, and if associated with polyarticular disease it should be treated like polyarthritis. Of note, NSAIDs have not demonstrated efficacy in dactylitis.

Given the lack of strong data on oligoarticular PsA, this recommendation was based more on expert opinion than on hard data (level of evidence, 4; grade of recommendation: C).

Recommendation 6: In patients with peripheral arthritis and an inadequate response to at least one csDMARD, therapy with a bDMARD should be commenced; when there is relevant skin involvement, an IL-17 inhibitor or IL-12/23 inhibitor may be preferred.

This recommendation addresses patients with peripheral arthritis, after failure or intolerance to at least one csDMARD. In these patients, the taskforce recommends a bDMARD. In some patients, especially those without bad prognostic factors or those with mild disease activity, it may be indicated to rotate to 
a second csDMARD before starting a bDMARD, as previously outlined in the 2015 recommendations. ${ }^{12}$

The taskforce extensively discussed the legitimacy of a bDMARD as first DMARD strategy; the discussion focused on efficacy and safety, as well as on costs. The taskforce was of the opinion that many patients respond satisfactorily to MTX, while tolerating the drug well. These patients would be subjected to overtreatment if starting a bDMARD immediately rather than waiting for 3 months to determine if a response to MTX has occurred (see recommendations 9 and 10). A good example is revealed in the SEAM-PsA trial. However, if entheseal or axial inflammatory involvement predominates, earlier use of bDMARDs is proposed, since csDMARDs are ineffective in these conditions (please see recommendations 9 and 10).

Whereas the 2015 recommendation stated that it was 'usual practice' to start a TNFi in comparison with other bDMARDs, the current update does not distinguish anymore between TNFi, IL-12/23 inhibitor (IL-12/23i) and IL-17 inhibitor (IL-17i). The SLR reconfirmed the efficacy of TNFi in PsA, and there are now reassuring long-term safety data with these drugs, including data indicating that the incidence of malignancies is not increased. ${ }^{54} 55$ Drugs targeting IL-12/23 and IL-17 are also consistently efficacious in comparison with placebo and long-term safety seems favourable. ${ }^{1}$ In addition to secukinumab, a second IL-17i, ixekizumab, has been approved since the 2015 recommendations, showing a similar efficacy and safety profile, which further reassured the taskforce. ${ }^{1456}$ Importantly, a head-to-head trial of ixekizumab versus the TNFi adalimumab showed similar efficacy of ixekizumab and adalimumab for musculoskeletal manifestations. ${ }^{57}$

Of note, efficacy in joints appeared numerically less for the IL-12/23i ustekinumab; however, observational data indicate similar magnitudes of response versus TNFi, and a formal headto-head trial is currently lacking. ${ }^{135}$ Furthermore, the taskforce noted that recent studies with biologicals targeting the IL-23-p19 subunit (guselkumab, risankizumab, tildrakizumab) appear encouraging, and that targeting this pathway has shown excellent efficacy in psoriasis. ${ }^{59-63}$ Thus, a suggested order between different targeted pathways is intentionally not given in this recommendation.

The total safety picture of these three categories of bDMARDs appeared acceptable in our SLR. ${ }^{1}$ The risks of TNFi are well known from large registries for long-term safety including these drugs. IL-17i may increase the incidence of (mild) localised candidiasis, and monitoring for a possible increased risk of inflammatory bowel disease is still ongoing. ${ }^{64}$ In any case, safety must always be considered carefully in every patient; more complete information regarding the safety aspects of bDMARDs is provided in the drugs' package inserts.

Taking together data on efficacy and safety, with regard to the treatment of arthritis in PsA, the taskforce found no reason to currently prioritise one of these bDMARDs over another one (as shown also in figure 1); costs should also be taken into account, and these may vary at the country level.

In contrast, both IL-12/23i and IL-17i have shown greater efficacy in skin than TNFi, in head-to-head trials of psoriasis and $\mathrm{PsA}^{626566}$; this evidence justifies the second half of the recommendation, which encourages the use of an IL-12/23i or IL-17i in patients with relevant skin involvement, where 'relevant' is defined (as above) as either extensive or as important to the patient.

When choosing a first bDMARD, the differential impact on certain musculoskeletal and non-musculoskeletal manifestations as well as comorbidities such as metabolic syndrome has to be considered. While important skin involvement was already mentioned, IL-12/23 inhibition may not be effective for axial involvement; IL-17 inhibition may not be appropriate for patients with concomitant inflammatory bowel disease for which monoclonal antibodies to TNF and IL-12/23 inhibitors are approved; and in the presence of uveitis, a monoclonal antibody to TNF may be the preferred first and second bDMARD because of respective approval. ${ }^{6768}$ On the other hand, regarding comorbidities, the paucity of relevant data precludes firm recommendations at present; this has been added to the research agenda.

The issue of monotherapy with bDMARDs versus combination therapy with a csDMARD was discussed. ${ }^{69} 70$ The current recommendation is to continue MTX with a bDMARD (using the latter as an add-on strategy) in patients already taking this drug and tolerating it well, but the taskforce admitted that to date there is no clear evidence that combination therapy is more efficacious than monotherapy, aside from a slight reduction of immunogenicity that is of doubtful clinical significance. ${ }^{71} \mathrm{We}$ suggest that MTX dose may be reduced in subjects showing a good biological drug response, especially when there are concerns about MTX toxicity. However, more data are needed and this point was put into the research agenda.

Recommendation 7: In patients with peripheral arthritis and an inadequate response to at least one CSDMARD and at least one bDMARD, or when a bDMARD is not appropriate, a JAK inhibitor may be considered.

At this moment, the only JAK inhibitor (JAKi) approved for PsA is tofacitinib. Our SLR indicated tofacitinib may have similar efficacy as the TNFi adalimumab for joint involvement, but numerically lower efficacy in skin psoriasis. ${ }^{15} 72$ There also appears to be satisfactory efficacy of tofacitinib in TNFi insufficient-responder populations. ${ }^{1}$ According to European Medicines Agency approval, tofacitinib must be prescribed with MTX. Safety signals exist for some infections, especially herpes zoster, as well as a recent signal for deep vein thrombosis especially with a high dose of tofacitinib which is not approved for PsA, but also the usual $5 \mathrm{mg}$ twice daily dose particularly in those with cardiovascular risk factors and older patients. ${ }^{1572} 73$

To date, two other JAKis are in development phases for PsA. Filgotinib showed promising efficacy in a phase II trial and upadacitinib was approved for use in rheumatoid arthritis shortly after the development of these recommendations, and also showed encouraging results in PsA. ${ }^{16}$

Taking these elements into account, as well as the general principle of favouring drugs with robust long-term safety data, the taskforce proposed JAKi either after inadequate response or intolerance to at least one bDMARD, or when a bDMARD is considered not appropriate. 'Not appropriate' means, for example, non-adherence to injections or a strong patient preference for an oral drug (in accordance with the overarching principle A concerning 'shared decision making'). However, the group agreed that normally the step-up approach would be a csDMARD followed by a bDMARD, and subsequently another bDMARD or a JAKi.

As new data become available, the current positioning of JAKis may evolve; this will justify an update of the recommendations if appropriate.

Recommendation 8: In patients with mild disease and an inadequate response to at least one csDMARD, in whom neither a bDMARD nor a JAK inhibitor is appropriate, a PDE4 inhibitor may be considered.

Similar to the 2015 update, this recommendation reserves a special place for apremilast: it should be used only when csDMARD therapy has failed and bDMARDs and JAKi are not appropriate; however, the taskforce considered that the value of 
apremilast may be found in treating patients with relatively mild disease or those in whom other agents are contraindicated, such as in patients with chronic infections. Mild disease is defined here as only few joints (four or less, thus oligoarticular disease), lower disease activity by composite scores and/or limited skin involvement. The reason for proposing the use of apremilast primarily for mild disease is that profound responses, such as Amercian College of Rheumatology 70\% (ACR70), are rarely seen in clinical trials with apremilast and are sometimes not different from placebo. ${ }^{11}{ }^{74-77}$ Moreover, radiographic data providing the disease-modifying potential of the drug are still lacking for apremilast, and therefore this drug may not be appropriate for patients with poor prognostic factors. A randomised controlled trial with apremilast in oligoarticular disease is currently under way. $^{78}$

The level of agreement with this recommendation was lower than for the others, suggesting diverse expert views on the place of this drug.

Recommendation 9: In patients with unequivocal enthesitis and insufficient response to NSAIDs or local glucocorticoid injections, therapy with a bDMARD should be considered.

Compared with recommendation 8 of the 2015 version, 'active enthesitis' has been replaced by 'unequivocal enthesitis', and the last part stating that 'current practice is to use a TNF-inhibitor' has been omitted. In patients with enthesitis, NSAIDs and local glucocorticoids are the first-line treatment; in case of insufficient response, intolerance or contraindication to NSAIDs, and given that csDMARDs are not efficacious for enthesitis, a bDMARD (targeting TNF, IL-17 or IL-12/23) may be used. 'Enthesitis' here refers to inflammation rather than entheseal pain, and the term 'unequivocal' has now been added to avoid overtreating triggerpoint pain that has other underlying causes (such as concomitant widespread pain syndromes). ${ }^{79}$ While sonography or MRI may underpin the presence of enthesitis, clinical examination should in principle suffice, and the number and pattern (asymmetrical) of painful entheses, as well as the presence of clinical swelling, should guide the clinician and allow a distinction from widespread pain syndromes. ${ }^{80-85}$ Entheseal disease is a complex issue in PsA and was also added to the research agenda.

Regarding bDMARDs, the taskforce now regards all bDMARDs as having efficacy of a similar magnitude for enthesitis and hence the preference for TNFi has been deleted. ${ }^{1}$

Recommendation 10: In patients with predominantly axial disease which is active and has insufficient response to NSAIDs, therapy with a bDMARD should be considered, which according to current practice is a TNF inhibitor; when there is relevant skin involvement, IL-17 inhibitor may be preferred.

In 2015, predominant (or highly significant) axial involvement was dealt with in recommendation 9. The phrasing of the current recommendation was partly aligned with the Assessment of Spondyloarthritis International Society (ASAS)/EULAR management recommendations for axial spondyloarthritis (axSpA), ${ }^{35}$ with the exception that these do not yet account for the use of IL-17is. It also reflects that in the situation of predominantly axial disease, TNFi would still represent the first bDMARD by usual practice. The taskforce discussed that secukinumab has demonstrated efficacy in axSpA, and recently has demonstrated efficacy in patients considered to have predominant axial PsA. ${ }^{86}$ However, the experience with IL-17 inhibition in terms of longterm efficacy and safety in axSpA and axial PsA is limited.
In predominantly axial PsA, in the presence of relevant skin involvement (as defined in the text below recommendation 4), an IL-17i would be preferred over a TNFi, given the greater efficacy of IL-17i in skin. ${ }^{57}$ Importantly, however, in case of concomitant inflammatory bowel disease or uveitis, a TNFi (monoclonal antibody) would be preferred.

Of note, the IL-12/23 pathway drugs did not demonstrate efficacy in axSpA. ${ }^{87}$ Thus, in light of lack of clear efficacy, drugs targeting IL-12/23 and abatacept (see also recommendation 11) are not indicated for patients with predominantly axial disease. ${ }^{87}$

Recommendation 11: In patients who fail to respond adequately to, or are intolerant of a bDMARD, switching to another bDMARD or tsDMARD should be considered, including one switch within a class. This recommendation, a slight expansion of the recommendation previously numbered as 10 , addresses first bDMARD failure or intolerance. Here we propose a switch either to another bDMARD or to a tsDMARD, especially a JAKi. Novel data on switches are limited, with only one such new study found through the SLR. ${ }^{88}$ Trials performed in TNFi insufficient responders have demonstrated efficacy of bDMARDs with another mode of action when TNFi has failed. ${ }^{56}$ However, another TNFi can also be used, since no head-to-head trial data are available that suggest switching between classes is different from switching within class. Finally, the taskforce agreed that while switching within class was a viable option, it would be logical to change class after a second failure within a given class (expert opinion). Studies addressing the best possible strategy after failure(s) of bDMARDs other than TNFi are lacking to date, and this topic was added to the research agenda.

The taskforce discussed the place of abatacept, which has been approved for use in PsA, and considered abatacept's place in the current algorithm should be limited to potential use after other bDMARDs have failed, given its relatively low efficacy. ${ }^{89}$

\section{Recommendation 12: In patients in sustained remission, cautious} tapering of DMARDs may be considered.

This is a new recommendation, primarily based on broad consensus among experts in the absence of solid trial data. Sparse data suggest a certain risk of relapse (either for joints or skin) when tapering. ${ }^{90-95}$ Still, the taskforce decided to offer guidance on tapering, since it was felt an important aspect of modern management, especially when sustained remission has been achieved, to mitigate treatment-related risks, to meet patients' desires and demands, and to reduce cost of treatment.

Tapering was considered appropriate only in the context of sustained remission, defined here as complete remission (rather than low disease activity) for at least six consecutive months. ${ }^{32}$

This point was deliberately phrased tentatively, with a recommendation to taper with great caution, as a consequence of shared decision-making based on comprehensive patient information. The recommendation does not have the intention to push clinicians towards stopping treatment but rather to try finding the smallest effective dose, either through dose reduction or interval lengthening. Best possible tapering strategies were also added as an item to the research agenda (table 3 ).

\section{DISCUSSION}

Since the last update of these recommendations, new information has accumulated on the efficacy and safety of established drugs and treatment strategies, but also on newer agents such as IL-17is and IL-12/23is as well as JAKis. Thus, while these updated recommendations continue to integrate the established 
as well as the new information, they also continue to attempt covering the broad spectrum of disease severity that best reflects clinical practice, in order to guide clinicians and other stakeholders involved in treating patients with PsA with a simple algorithm and set of recommendations that can easily be translated into daily clinical practice. Importantly, all of this information is based on a thorough SLR and on conclusions by an expert committee that primarily used evidence to derive its recommendations, but also specialists' opinions, where evidence was lacking or was insufficient.

These recommendations have been modified substantially compared with the 2015 update, since new drugs have entered the market and more evidence about existing drugs has accrued (table 2). In particular, longer term safety data have become available, which add importantly to the robustness of the evidence. In general this update adheres to the previous structure of these recommendations in all respects. (1) We continue to separate this guidance document into overarching (general) treatment approaches and individual therapeutic recommendations. (2) We continue to recommend targeting clinical remission (primarily for early disease) or, alternatively, low disease activity (for established disease); in this light, a moderate let alone high disease activity state is unacceptable, unless comorbidities or other patient factors preclude treatment advances. (3) We continue to recommend a T2T strategy; the $\mathrm{T} 2 \mathrm{~T}$ recommendations have been recently updated and propose at least 50\% improvement of the composite measure within 3 months and achievement of the target within 6 months from treatment initiation, thus requiring the use of a continuous measure of disease activity to follow patients longitudinally and also reflect patient perceptions. (4) As before, we structure the pathway to a successful outcome into four phases, an initial phase which might suffice in very mild disease or necessitate advancement to one of the next two phases; a second phase focusing on the use of csDMARDs; a third phase for patients who failed to reach the target in phase II and/or phase I when exhibiting predominant axial or entheseal disease; and a fourth phase for those who failed phase III.

Further, we provide a quantitative rather than only a qualitative assessment of the evidence available for all agents dealt with-not every drug that is approved must be assigned the same level of applicability if the database suggests differences, even if head-to-head trials are largely missing. ${ }^{57}$ In our view it is the task of expert committees to judge and qualify available data to the best of their knowledge for the best outcomes of the patients by interpreting the relevance of the available data after a thorough debate and decision-making process. Thus, we weighed the evidence provided by the SLR in the course of the discussion and voting process. We aimed and aim at providing recommendations that are not only truthful, but also have face validity and thus usefulness.

In preparing the recommendations, the taskforce adhered to the EULAR operating procedures for the development of recommendations and assessed evidence levels according to the Oxford Evidence Based Medicine approach. ${ }^{21} 22$ Finally, the focus of this taskforce was on the musculoskeletal manifestations and, while mentioning the need to consult other specialists, these recommendations, in line with the composition of the taskforce, are primarily aimed at rheumatologists and their patients with PsA. Recommendations for other specialists should be sought in the respective specialty literature.

Unlike other organisations that have also released treatment recommendations for PsA, EULAR has decided to not pursue Grading of Recommendations Assessment, Development and Evaluation (GRADE) methodology for prioritising available treatments. While GRADE methodology is widely used and highly appreciated for properly judging quality of available evidence, experts within EULAR feel that GRADE puts too much emphasis on the methodology itself and tends to downplay prevalent but poorly investigated clinical scenarios for which clinicians still seek guidance. A good example of the latter is the place of MTX as first-line treatment: while we acknowledge the absence of good clinical evidence for MTX as first-line DMARD, we still recommend it as such, by virtue of long-term positive clinical experience, including data from registries, as well as recent encouraging results, such as in the TICOPA and SEAM-PsA trials, ${ }^{42}$ long-term positive clinical experience, widespread fame and low treatment cost. We think this set of practical recommendations, which has been developed according to general principles of evidence-based medicine, will help rheumatologists in choosing the most appropriate and cost-effective drug treatment for every patient with PsA and in every clinical scenario, even though the body of scientific evidence may fall short in many aspects of the disease. We recognise the fields in which evidence is sparse or lacking are crucially important, and they frame the research agenda. We hope that clinical researchers will be influenced by and appreciate the clinical questions summarised in the research agenda, and design experiments or trials aiming at providing resolution to these research questions.

All these aspects have allowed us to provide what the taskforce believes is the right place for the different drug classes in the treatment algorithm. Still, the EULAR PsA recommendations have preserved their original character which they share with other sets of EULAR recommendations for different inflammatory diseases. Important elements thereof are a graduated approach favouring well-known csDMARDs as first-line drugs and allowing escalation to bDMARDs when necessary; preferring drugs with an established long-term track record for safety over those that have recently been approved; and attention for tapering and stopping treatment if possible.

As before, the recommendations make it clear that one drug does not fit all and stipulate the role of the phenotypes and patient characteristics in the decision-making process of starting and stopping treatments. Shared decision-making has become an integral part of the management of patients with PsA. There is also more attention for 'prognostic profiling', paying more tribute to clinical reality; while the spectrum of patients with PsA included in trials is skewed towards patients with prognostically unfavourable polyarticular PsA, this type of PsA is a relatively rare condition in clinical practice, especially in the scenario of the initial early disease presentations in contemporary rheumatology practice. Thus, recommendations should also give guidance about how to address patients with milder oligoarticular or monoarticular disease.

Treatment decisions also have to take account of extramusculoskeletal disease manifestations such as inflammatory bowel disease or uveitis, aside from skin involvement, which require distinct therapies (anti-TNF monoclonal antibodies for uveitis, anti-TNF monoclonal antibodies or IL-12/23i for inflammatory bowel disease in the absence of axial involvement) just as they require distinct clinical evaluation. Importantly, these novel pieces of information only originated from the information that was obtained in the course of clinical trials of the various established and new compounds.

As before, the updated recommendations have been summarised in an algorithm. The EULAR algorithm (figure 1) continues to account for the musculoskeletal diversity of PsA and should be easy to follow; where new therapies are particularly efficacious regarding skin involvement, a special note is 
provided within the algorithm (see also respective footnotes), thus allowing to follow these management recommendations straightforwardly throughout the evolution of the disease.

In summary, the updated treatment recommendations for patients with PsA living in many different countries, under the influence of very different healthcare systems, support decisionmaking for the management of PsA and address the entire spectrum of the disease. An update will be needed within 2-4 years, as new data arise in PsA.

\section{Author affiliations}

'Institut Pierre Louis d'Epidémiologie et de Santé Publique, INSERM, Sorbonne Universite, Paris, France

${ }^{2}$ APHP.Sorbonne Universite, Rheumatology Department, Hopital Universitaire Pitie Salpetriere, Paris, France

${ }^{3}$ Ruhr-Universität Bochum, Rheumazentrum Ruhrgebiet, Herne, Germany

${ }^{4}$ Division of Rheumatology, Department of Medicine 3; 2nd Department of Medicine, Hietzing Hospital, Medical University of Vienna, Vienna, Austria

${ }^{5}$ EULAR, Zurich, Switzerland

${ }^{6}$ Institute of Infection, Immunity and Inflammation, University of Glasgow, Glasgow, UK

${ }^{7}$ Hopital Cochin, Rheumatology, Université Paris Descartes, Paris, France

${ }^{8}$ Danish Hospital for Rheumatic Diseases, University Hospital of Southern Denmark, Sønderborg, Denmark

${ }^{9}$ Department of Regional Health Research, University of Southern Denmark, Odense, Denmark

${ }^{10}$ LTHT, Leeds NIHR Biomedical Research Centre, Leeds, UK

${ }^{11}$ Leeds Institute of Rheumatic and Musculoskeletal Medicine, University of Leeds, Leeds, UK

${ }^{12}$ Division of Rheumatology, Department of Medicine 3, Medical University of Vienna, Vienna, Austria

${ }^{13}$ Research Center of Rheumatic Diseases, Sf Maria Hospital, Carol Davila University of Medicine and Pharmacy, Bucharest, Romania

${ }^{14} 3$ rd Department of Rheumatology, National Institute of Rheumatology and Physiotherapy, Budapest, Hungary

${ }^{15}$ Patient Research Partner, EULAR, Oslo, Norway

${ }^{16}$ Dermatology, University Hospitals of Geneva, Geneva, Switzerland

${ }^{17}$ Rheumatology and Clinical Immunology, Charite University Hospital Berlin, Berlin, Germany

${ }^{18}$ Arthritis Unit, Department of Rheumatology and IDIBAPS, Hospital Clinic,

Barcelona, Spain

${ }^{19}$ Institute of Rheumatology, Belgrade University School of Medicine, Belgrade, Serbia

${ }^{20}$ Department of Biomedicine, Aarhus University, Aarhus C, Denmark

${ }^{21}$ Department of Rheumatology, Aarhus Universitetshospital, Aarhus, Denmark

${ }^{22}$ Rheumatology, Diakonhjemmet Hospital, Oslo, Norway

${ }^{23}$ Amsterdam Rheumatology Center, AMC, Amsterdam, The Netherlands

${ }^{24}$ Rheumatology, Zuyderland MC, Heerlen, The Netherlands

${ }^{25}$ Laboratory of Tissue Homeostasis and Disease, Skeletal Biology and Engineering Research Center, KU Leuven, Leuven, Flanders, Belgium

${ }^{26}$ Rheumatology, KU Leuven University Hospitals Leuven, Leuven, Flanders, Belgium

${ }^{27}$ Department of Rheumatology, Infectious Diseases and Rheumatology, Charité Universitätsmedizin Berlin, Berlin, Germany

${ }^{28}$ Epidemiology, German Rheumatism Research Center Berlin, Berlin, Germany

${ }^{29}$ Rheumatology, Hospital de Egas Moniz, Lisboa, Portugal

${ }^{30}$ Universidade Nova de Lisboa Centro de Estudos de Doencas Cronicas, Lisboa, Portugal

${ }^{31}$ Internal Medicine, University of Erlangen-Nuremberg, Erlangen, Germany

${ }^{32}$ Centre for Arthritis and Rheumatic Disease, Dublin Academic Medical Centre, St Vincent's University Hospital, Dublin, Ireland

${ }^{33}$ Department of Internal Medicine and Pediatrics, VIB Center for Inflammation Research, Ghent University, Gent, Belgium

${ }^{34}$ Rheumatology, Leiden University Medical Center, Leiden, The Netherlands

${ }^{35}$ Division of Rheumatology, Department of Medicine 3, Medical University of Vienna, Vienna, Wien, Austria

${ }^{36}$ 2nd Department of Medicine, Hietzing Hospital, Vienna, Wien, Austria

Twitter Tue Wenzel Kragstrup @KragstrupTW and Santiago Andres Rodrigues Manica@R_M_Santiago

Contributors All authors have contributed to this work and approved the final version.

Funding This study was funded by the European League Against Rheumatism. DMG and HM-O are supported by the National Institute for Health Research (NIHR) Leeds Biomedical Research Centre (LBRC). The views expressed are those of the authors and not necessarily those of the (UK) National Health Service (NHS), the NIHR or the (UK) Department of Health.
Competing interests LG: AbbVie, Biogen, Celgene, Janssen, Lilly, Mylan, Novartis, Pfizer, Sandoz, Sanofi-Aventis, UCB. XB: AbbVie, Amgen, BMS, Celgene, Chugai, Hexal, Janssen, Lilly, MSD, Mylan, Novartis, Pfizer, Sandoz, UCB. AK: Bristol-Myers Squibb, Celgene, Eli Lilly, Gilead, Merck Sharp and Dohme, Novartis, Pfizer. MdW: Through Stichting Tools from AbbVie, BMS, Celgene, Eli Lilly, Janssen-Cilag, Novartis, Pfizer, Roche. IM: AbbVie, BMS, Lilly, Novartis, Celgene, Gilead, Janssen, Boehringer, UCB, Pfizer. MD: AbbVie, BMS, Janssen, Lilly, Novartis, Merck, Pfizer, UCB. JP: BMS, Pfizer. DGM: AbbVie, BMS, Celgene, Eli Lilly, Janssen, Merck, Novartis, Pfizer, UCB. DA: AbbVie, Amgen, Gilead, Lilly, Merck, Novartis, Pfizer, Roche, Sandoz, Sanofi/ Genzyme, Sobi. AB: AbbVie, Amgen, AstraZeneca, Angelini, AlfaSigma, BMS, BerlinChemie, Egis, Ewopharma, GSK, Lilly, Mylan, MSD, Novartis, Pfizer, Roche, Sandoz, Sanofi, Teva, UCB, Zentiva. PVB: AbbVie, Celgene, Lilly, MSD, Novartis, Pfizer, Richter. HB: Pfizer. W-HB: AbbVie, Almirall, BMS, Celgene, Leo, Lilly, Novartis, Pfizer, UCB. GRB: AbbVie, Celgene, Lilly, MSD, Novartis, Pfizer. JDC: Celgene, Eli Lilly, Gilead, Janssen, Novartis, Pfizer, UCB. NSD: AbbVie, Boehringer Ingelheim, Gedeon Richter, Lilly, Novartis, Pfizer, Roche. TWK: Bristol-Myers Squibb, Eli Lilly, Novartis, Pfizer, UCB. TKK: AbbVie, Amgen, Biogen, BMS, Celltrion, Egis, Eli Lilly, Ewopharma, Hikma, Hospira/Pfizer, MSD, Mylan, Orion Pharma, Roche, Sandoz, Sanofi, UCB. RBML: AbbVie, Boehringer Ingelheim, Bristol-Myers Squibb, Celgene, Eli Lilly, Galapagos, Gilead, MSD, Novartis, Pfizer, UCB. RJUL is Director of Rheumatology Consultancy; AbbVie, Celgene, Eli Lilly, Janssen, Novartis, Pfizer, UCB. HM-O: AbbVie, Celgene, Eli Lilly, Janssen, Novartis, Pfizer, Takeda, UCB. DP: AbbVie, BMS, Celgene, Janssen, Lilly, MSD, Novartis, Pfizer, Roche, UCB. SARM: Janssen, MSD, Novartis. GS: AbbVie, BMS, Celgene, Gilead, Janssen, Lilly, Novartis, Pfizer, Roche, UCB. DJV: AbbVie, Biogen, Boehringer Ingelheim, HealthBeacon, Janssen, Lilly, MSD, Novartis, Pfizer, Roche, UCB. FEVdB: AbbVie, Celgene, Eli Lilly, Galapagos/Gilead, Janssen, Merck, Novartis, Pfizer, UCB. DvdH: AbbVie, Amgen, Astellas, AstraZeneca, BMS, Boehringer Ingelheim, Celgene, Cyxone, Daiichi, Eisai, Eli Lilly, Galapagos, Gilead, GlaxoSmithKline, Janssen, Merck, Novartis, Pfizer, Regeneron, Roche, Sanofi, Takeda, UCB Pharma; Director of Imaging Rheumatology. JSS: grants to institution from AbbVie, AstraZeneca, Janssen, Lilly, Merck Sharp \& Dohme, Pfizer and Roche; speaker for AbbVie, Amgen, AstraZeneca, Astro, Bristol-Myers Squibb, Celgene, Celltrion, Chugai, Gilead, ILTOO Pharma, Janssen, Lilly, Merck Sharp \& Dohme, Novartis-Sandoz, Pfizer, Roche, Samsung, Sanofi and UCB.

Patient and public involvement Patients and/or the public were involved in the design, or conduct, or reporting, or dissemination plans of this research.

Patient consent for publication Not required.

Provenance and peer review Not commissioned; externally peer reviewed.

Open access This is an open access article distributed in accordance with the Creative Commons Attribution Non Commercial (CC BY-NC 4.0) license, which permits others to distribute, remix, adapt, build upon this work non-commercially, and license their derivative works on different terms, provided the original work is properly cited, appropriate credit is given, any changes made indicated, and the use is non-commercial. See: http://creativecommons.org/licenses/by-nc/4.0/.

\section{ORCID iDs}

Laure Gossec http://orcid.org/0000-0002-4528-310X

Andreas Kerschbaumer http://orcid.org/0000-0002-6685-8873

Maarten de Wit http://orcid.org/0000-0002-8428-6354

Jette Primdahl http://orcid.org/0000-0002-1049-4150

Juan D Canete http://orcid.org/0000-0001-7932-2632

Denis Poddubnyy http://orcid.org/0000-0002-4537-6015

Santiago Andres Rodrigues Manica http://orcid.org/0000-0002-7217-0469

Georg Schett http://orcid.org/0000-0001-8740-9615

Douglas J Veale http://orcid.org/0000-0003-2802-4971

Désirée van der Heijde http://orcid.org/0000-0002-5781-158X

\section{REFERENCES}

1 Kerschbaumer A, Smolen JS, Dougados M, et al. Pharmacological treatment of psoriatic arthritis: a systematic literature research for the 2019 update of the EULAR recommendations for the management of psoriatic arthritis. Ann Rheum Dis 2016.

2 Fernández-Carballido C, Martín-Martínez MA, García-Gómez C, et al. Impact of comorbidity on physical function in patients with ankylosing spondylitis and psoriatic arthritis attending rheumatology clinics. Results from the CAR diovascular in rheu MA tology (CARMA) study. Arthritis Care Res.

3 Rodriguez-Moreno J, Bonet M, Del Blanco-Barnusell J, et al. Mutilating/resorptive arthritis. A study of 24 patients in a series of 360 patients with psoriatic arthritis. Reumatol Clin 2013:9:38-41.

4 Ferguson LD, Siebert S, McInnes IB, et al. Cardiometabolic comorbidities in RA and PsA: lessons learned and future directions. Nat Rev Rheumatol 2019;15:461-74.

5 Gudu T, Etcheto A, de Wit M, et al. Fatigue in psoriatic arthritis - a cross-sectional study of 246 patients from 13 countries. Joint Bone Spine 2016:83:439-43.

6 Helliwell PS, Ruderman EM, History N. Natural history, prognosis, and socioeconomic aspects of psoriatic arthritis. Rheum Dis Clin North Am 2015;41:581-91.

7 Gudu T, Gossec L. Quality of life in psoriatic arthritis. Expert Rev Clin Immunol 2018;14:405-17. 
8 Gossec L, de Wit M, Kiltz U, et al. A patient-derived and patient-reported outcome measure for assessing psoriatic arthritis: elaboration and preliminary validation of the psoriatic arthritis impact of disease (PsAID) questionnaire, a 13-country EULAR initiative. Ann Rheum Dis 2014;73:1012-9.

9 Desthieux C, Granger B, Balanescu AR, et al. Determinants of patient-physician discordance in global assessment in psoriatic arthritis: a multicenter European study. Arthritis Care Res 2017;69:1606-11.

10 Orbai A-M, de Wit M, Mease P, et al. International patient and physician consensus on a psoriatic arthritis core outcome set for clinical trials. Ann Rheum Dis 2017;76:673-80.

11 Cutolo M, Myerson GE, Fleischmann RM, et al. A phase III, randomized, controlled trial of apremilast in patients with psoriatic arthritis: results of the PALACE 2 trial. J Rheumatol 2016:43:1724-34.

12 Kavanaugh A, Husni ME, Harrison DD, et al. Safety and efficacy of intravenous golimumab in patients with active psoriatic arthritis: results through week twenty-four of the GO-VIBRANT study. Arthritis Rheumatol 2017;69:2151-61.

13 Ritchlin C, Rahman P, Kavanaugh A, et al. Efficacy and safety of the anti-IL-12/23 p40 monoclonal antibody, ustekinumab, in patients with active psoriatic arthritis despite conventional non-biological and biological anti-tumour necrosis factor therapy: 6-month and 1-year results of the phase 3, multicentre, double-blind, placebocontrolled, randomised PSUMMIT 2 trial. Ann Rheum Dis 2014;73:990-9.

14 Mease PJ, van der Heijde D, Ritchlin CT, et al. Ixekizumab, an interleukin-17A specific monoclonal antibody, for the treatment of biologic-naive patients with active psoriatic arthritis: results from the 24-week randomised, double-blind, placebo-controlled and active (adalimumab)-controlled period of the phase III trial SPIRIT-P1. Ann Rheum Dis 2017:76:79-87.

15 Mease P, Hall S, FitzGerald O, et al. Tofacitinib or adalimumab versus placebo for psoriatic arthritis. N Eng/ J Med 2017;377:1537-50.

16 Mease P, Coates LC, Helliwell PS, et al. Efficacy and safety of filgotinib, a selective Janus kinase 1 inhibitor, in patients with active psoriatic arthritis (EQUATOR): results from a randomised, placebo-controlled, phase 2 trial. Lancet 2018;392:2367-77.

17 Gossec L, Smolen JS, Gaujoux-Viala C, et al. European League against rheumatism recommendations for the management of psoriatic arthritis with pharmacological therapies. Ann Rheum Dis 2012;71:4-12.

18 Gossec L, Smolen JS, Ramiro S, et al. European League against rheumatism (EULAR) recommendations for the management of psoriatic arthritis with pharmacological therapies: 2015 update. Ann Rheum Dis 2016;75:499-510.

19 Coates LC, Kavanaugh A, Mease PJ, et al. Group for research and assessment of psoriasis and psoriatic arthritis 2015 treatment recommendations for psoriatic arthritis. Arthritis Rheumatol 2016;68:1060-71.

20 Singh JA, Guyatt G, Ogdie A, et al. Special article: 2018 American College of Rheumatology/National psoriasis Foundation guideline for the treatment of psoriatic arthritis. Arthritis Rheumatol 2019;71:5-32.

21 van der Heijde D, Aletaha D, Carmona L, et al. 2014 update of the EULAR standardised operating procedures for EULAR-endorsed recommendations. Ann Rheum Dis 2015:74:8-13.

22 CEBM. Oxford centre for evidence-based Medicine - Levels of evidence (March 2009), 2009. Available: https://www.cebm.net/2009/06/oxford-centre-evidence-basedmedicine-levels-evidence-march-2009/

23 Wendling D, Lukas C, Prati C, et al. 2018 update of French Society for rheumatology (SFR) recommendations about the everyday management of patients with spondyloarthritis. Joint Bone Spine 2018;85:275-84.

24 Husni ME, Merola JF, Davin S. The psychosocial burden of psoriatic arthritis. Semin Arthritis Rheum 2017;47:351-60.

25 Mitulescu TC, Popescu C, Naie A, et al. Acute anterior uveitis and other extra-articular manifestations of spondyloarthritis. J Med Life 2015;8:319-25.

26 Peluso R, lervolino S, Vitiello M, et al. Extra-Articular manifestations in psoriatic arthritis patients. Clin Rheumatol 2015;34:745-53.

27 Siegel EL, Orbai A-M, Ritchlin CT. Targeting extra-articular manifestations in PSA: a closer look at enthesitis and dactylitis. Curr Opin Rheumatol 2015;27:111-7.

28 Agca R, Heslinga SC, Rollefstad S, et al. EULAR recommendations for cardiovascular disease risk management in patients with rheumatoid arthritis and other forms of inflammatory joint disorders: 2015/2016 update. Ann Rheum Dis 2017;76:17-28.

29 Michelsen B, Kristianslund EK, Sexton J, et al. Do depression and anxiety reduce the likelihood of remission in rheumatoid arthritis and psoriatic arthritis? data from the prospective multicentre NOR-DMARD study. Ann Rheum Dis 2017;76:1906-10.

30 Smolen JS, Breedveld FC, Burmester GR, et al. Treating rheumatoid arthritis to target: 2014 update of the recommendations of an international Task force. Ann Rheum Dis 2016;75:3-15.

31 Smolen JS, Braun J, Dougados M, et al. Treating spondyloarthritis, including ankylosing spondylitis and psoriatic arthritis, to target: recommendations of an international Task force. Ann Rheum Dis 2014;73:6-16.

32 Smolen JS, Schöls M, Braun J, et al. Treating axial spondyloarthritis and peripheral spondyloarthritis, especially psoriatic arthritis, to target: 2017 update of recommendations by an international Task force. Ann Rheum Dis 2018:77:3-17.

33 Gorlier C, Orbai A-M, Puyraimond-Zemmour D, et al. Comparing patient-perceived and physician-perceived remission and low disease activity in psoriatic arthritis: an analysis of 410 patients from 14 countries. Ann Rheum Dis 2019;78:201-8.
34 Gossec L, McGonagle D, Korotaeva T, et al. Minimal disease activity as a treatment target in psoriatic arthritis: a review of the literature. J Rheumatol 2018;45:6-13.

35 van der Heijde D, Ramiro S, Landewé R, et al. 2016 update of the ASAS-EULAR management recommendations for axial spondyloarthritis. Ann Rheum Dis 2017;76:978-91

36 Kalyoncu U, Bayindir Özün, Ferhat Öksüz M, et al. The psoriatic arthritis registry of turkey: results of a multicentre registry on 1081 patients. Rheumatology 2017; 56:279-86.

37 Kingsley GH, Kowalczyk A, Taylor H, et al. A randomized placebo-controlled trial of methotrexate in psoriatic arthritis. Rheumatology 2012:51:1368-77.

38 Coates LC, Moverley AR, McParland L, et al. Effect of tight control of inflammation in early psoriatic arthritis (TICOPA): a UK multicentre, open-label, randomised controlled trial. Lancet 2015:386:2489-98.

39 Heiberg MS, Kaufmann C, Rødevand E, et al. The comparative effectiveness of anti-TNF therapy and methotrexate in patients with psoriatic arthritis: 6 month results from a longitudinal, observational, multicentre study. Ann Rheum Dis 2007:66:1038-42.

40 Heiberg MS, Koldingsnes W, Mikkelsen K, et al. The comparative one-year performance of anti-tumor necrosis factor alpha drugs in patients with rheumatoid arthritis, psoriatic arthritis, and ankylosing spondylitis: results from a longitudinal, observational, multicenter study. Arthritis Rheum 2008;59:234-40.

41 Lie E, van der Heijde D, Uhlig T, et al. Effectiveness and retention rates of methotrexate in psoriatic arthritis in comparison with methotrexate-treated patients with rheumatoid arthritis. Ann Rheum Dis 2010;69:671-6.

42 Mease PJ, Gladman DD, Collier DH, et al. Etanercept and methotrexate as monotherapy or in combination for psoriatic arthritis: primary results from a randomized, controlled phase III trial. Arthritis Rheumatol 2019;71:1112-24.

43 Nikiphorou E, Negoescu A, Fitzpatrick JD, et al. Indispensable or intolerable? methotrexate in patients with rheumatoid and psoriatic arthritis: a retrospective review of discontinuation rates from a large UK cohort. Clin Rheumatol 2014;33:609-14.

44 Carrascosa JM, de la Cueva P, Ara M, et al. Methotrexate in moderate to severe psoriasis: review of the literature and expert recommendations. Actas Dermosifiliogr 2016;107:194-206.

45 Menter A, Gelfand JM, Connor C, et al. Joint AAD-NPF guidelines of care for the management of psoriasis with systemic non-biological therapies. J Am Acad Dermatol 2020;9622.

46 SmithKC. Systemic therapy of psoriasis using methotrexate. Skin Therapy Lett 2000;6:1-2; 5 .

47 Armstrong AW, Betts KA, Sundaram M, et al. Comparative efficacy and incremental cost per Responder of methotrexate versus apremilast for methotrexate-naïve patients with psoriasis. J Am Acad Dermatol 2016;75:740-6.

48 Ogdie A, Yu Y, Haynes K, et al. Risk of major cardiovascular events in patients with psoriatic arthritis, psoriasis and rheumatoid arthritis: a population-based cohort study. Ann Rheum Dis 2015;74:326-32.

49 Li L, Hagberg KW, Peng M, et al. Rates of cardiovascular disease and major adverse cardiovascular events in patients with psoriatic arthritis compared to patients without psoriatic arthritis. JCR: Journal of Clinical Rheumatology 2015;21:405-10.

50 Ramiro S, Smolen JS, Landewé R, et al. Pharmacological treatment of psoriatic arthritis: a systematic literature review for the 2015 update of the EULAR recommendations for the management of psoriatic arthritis. Ann Rheum Dis 2016;75:490-8.

51 Jadon DR, Shaddick G, Tillett W, et al. Psoriatic arthritis mutilans: characteristics and natural radiographic history. J Rheumatol 2015;42:1169-76

52 El Miedany Y, El Gaafary M, Youssef S, et al. Tailored approach to early psoriatic arthritis patients: clinical and ultrasonographic predictors for structural joint damage. Clin Rheumatol 2015;34:307-13.

53 Geijer M, Lindqvist U, Husmark T, et al. The Swedish early psoriatic arthritis registry 5-year followup: substantial radiographic progression mainly in men with high disease activity and development of Dactylitis. J Rheumatol 2015;42:2110-7.

54 Hellgren K, Dreyer L, Arkema EV, et al. Cancer risk in patients with spondyloarthritis treated with TNF inhibitors: a collaborative study from the ARTIS and DANBIO registers. Ann Rheum Dis 2017;76:105-11.

55 Costa L, Caso F, Del Puente A, et al. Incidence of malignancies in a cohort of psoriatic arthritis patients taking traditional disease modifying antirheumatic drug and tumor necrosis factor inhibitor therapy: an observational study. J Rheumatol 2016;43:2149-54.

56 Nash P, Kirkham B, Okada M, et al. Ixekizumab for the treatment of patients with active psoriatic arthritis and an inadequate response to tumour necrosis factor inhibitors: results from the 24-week randomised, double-blind, placebo-controlled period of the SPIRIT-P2 phase 3 trial. The Lancet 2017;389:2317-27.

57 Mease PJ, Smolen JS, Behrens F, et al. A head-to-head comparison of the efficacy and safety of ixekizumab and adalimumab in biological-naïve patients with active psoriatic arthritis: 24-week results of a randomised, open-label, blinded-assessor trial. Ann Rheum Dis 2020;79:123-31.

58 McInnes IB, Kavanaugh A, Gottlieb AB, et al. Efficacy and safety of ustekinumab in patients with active psoriatic arthritis: 1 year results of the phase 3 , multicentre, double-blind, placebo-controlled PSUMMIT 1 trial. Lancet 2013;382:780-9. 
59 Deodhar A, Gottlieb AB, Boehncke W-H, et al. Efficacy and safety of guselkumab in patients with active psoriatic arthritis: a randomised, double-blind, placebo-controlled, phase 2 study. Lancet 2018;391:2213-24.

60 Mease PJ, Kellner H, Morita A, et al. OP0307 efficacy and safety of risankizumab, a selective IL-23p19 inhibitor, in patients with active psoriatic arthritis over 24 weeks: results from a phase 2 trial. Ann Rheum Dis 2018;77:200-1.

61 Blauvelt A, Papp KA, Griffiths CEM, et al. Efficacy and safety of guselkumab, an antiinterleukin-23 monoclonal antibody, compared with adalimumab for the continuous treatment of patients with moderate to severe psoriasis: results from the phase III, double-blinded, placebo- and active comparator-controlled voyage 1 trial. J Am Acad Dermatol 2017;76:405-17.

62 Reich K, Armstrong AW, Foley P, et al. Efficacy and safety of guselkumab, an antiinterleukin-23 monoclonal antibody, compared with adalimumab for the treatment of patients with moderate to severe psoriasis with randomized withdrawal and retreatment: results from the phase III, double-blind, placebo- and active comparatorcontrolled voyage 2 trial. J Am Acad Dermatol 2017;76:418-31.

63 Gordon KB, Strober B, Lebwohl M, et al. Efficacy and safety of risankizumab in moderate-to-severe plaque psoriasis (UItIMMa-1 and UItIMMa-2): results from two double-blind, randomised, placebo-controlled and ustekinumab-controlled phase 3 trials. Lancet 2018;392:650-61.

64 Mease PJ, Kavanaugh A, Reimold A, et al. Secukinumab provides sustained improvements in the signs and symptoms of psoriatic arthritis: final 5-year results from the phase 3 future 1 study. ACR Open Rheumatol 2020;2:18-25.

65 Blauvelt A, Reich K, Tsai T-F, et al. Secukinumab is superior to ustekinumab in clearing skin of subjects with moderate-to-severe plaque psoriasis up to 1 year: Results from the CLEAR study. J Am Acad Dermatol 2017;76:e69:60-9.

66 Papp KA, Blauvelt A, Bukhalo M, et al. Risankizumab versus ustekinumab for moderate-to-severe plaque psoriasis. N Engl J Med 2017;376:1551-60.

67 Schreiber S, Colombel J-F, Feagan BG, et al. Incidence rates of inflammatory bowel disease in patients with psoriasis, psoriatic arthritis and ankylosing spondylitis treated with secukinumab: a retrospective analysis of pooled data from 21 clinical trials. Ann Rheum Dis 2019;78:473-9.

68 So A, Inman RD. An overview of biologic disease-modifying antirheumatic drugs in axial spondyloarthritis and psoriatic arthritis. Best Pract Res Clin Rheumatol 2018:32:453-71.

69 Aaltonen K, Heinonen A, Joensuu J, et al. Effectiveness and drug survival of TNFinhibitors in the treatment of psoriatic arthritis: a prospective cohort study. Semin Arthritis Rheum 2017;46:732-9

70 Behrens F, Cañete JD, Olivieri I, et al. Tumour necrosis factor inhibitor monotherapy vs combination with MTX in the treatment of PSA: a systematic review of the literature. Rheumatology 2015;54:915-26.

71 Zisapel M, Zisman D, Madar-Balakirski N, et al. Prevalence of TNF- $\alpha$ blocker immunogenicity in psoriatic arthritis. J Rheumatol 2015;42:73-8.

72 Gladman D, Rigby W, Azevedo VF, et al. Tofacitinib for psoriatic arthritis in patients with an inadequate response to TNF inhibitors. N Engl J Med 2017;377:1525-36.

73 Ema confirms Xeljanz to be used with caution in patients at high risk of blood clots. Available: https://www.ema.europa.eu/en/news/ema-confirms-xeljanz-be-usedcaution-patients-high-risk-blood-clots [Accessed 2 Apr 2020].

74 Kavanaugh A, Mease PJ, Gomez-Reino JJ, et al. Treatment of psoriatic arthritis in a phase 3 randomised, placebo-controlled trial with apremilast, an oral phosphodiesterase 4 inhibitor. Ann Rheum Dis 2014;73:1020-6.

75 Edwards CJ, Blanco FJ, Crowley J, et al. Apremilast, an oral phosphodiesterase 4 inhibitor, in patients with psoriatic arthritis and current skin involvement: a phase III, randomised, controlled trial (PALACE 3). Ann Rheum Dis 2016;75:1065-73.

76 Wells AF, Edwards CJ, Kivitz AJ, et al. Apremilast monotherapy in DMARD-naive psoriatic arthritis patients: results of the randomized, placebo-controlled PALACE 4 trial. Rheumatology 2018;57:1253-63.
77 Nash P, Ohson K, Walsh J, et al. Early and sustained efficacy with apremilast monotherapy in biological-naïve patients with psoriatic arthritis: a phase IIIB, randomised controlled trial (active). Ann Rheum Dis 2018;77:690-8.

78 ClinicalTrials.gov. Efficacy, safety, and tolerability study of apremilast to treat early Oligoarticular psoriatic arthritis. Available: https://clinicaltrials.gov/ct2/show/ NCT03747939

79 Fan A, Pereira B, Tournadre A, et al. Frequency of concomitant fibromyalgia in rheumatic diseases: monocentric study of 691 patients. Semin Arthritis Rheum 2017;47:129-32

80 Kaeley GS, Eder L, Aydin SZ, et al. Enthesitis: a hallmark of psoriatic arthritis. Semin Arthritis Rheum 2018;48:35-43.

81 Marchesoni A, De Marco G, Merashli M, et al. The problem in differentiation between psoriatic-related polyenthesitis and fibromyalgia. Rheumatology 2018;57:32-40

82 Mease PJ, Karki C, Palmer JB, et al. Clinical characteristics, disease activity, and patient-reported outcomes in psoriatic arthritis patients with Dactylitis or Enthesitis: results from the Corrona psoriatic Arthritis/Spondyloarthritis registry. Arthritis Care Res 2017;69:1692-9.

83 Polachek A, Cook R, Chandran V, et al. The association between sonographic enthesitis and radiographic damage in psoriatic arthritis. Arthritis Res Ther 2017;19:189.

84 Polachek A, Li S, Chandran V, et al. Clinical Enthesitis in a prospective longitudinal psoriatic arthritis cohort: incidence, prevalence, characteristics, and outcome. Arthritis Care Res 2017;69:1685-91.

85 Schett G, Lories RJ, D'Agostino M-A, et al. Enthesitis: from pathophysiology to treatment. Nat Rev Rheumatol 2017;13:731-41.

86 Baraliakos X, Coates LC, Gossec L. Secukinumab improves axial manifestations in patients with psoriatic arthritis and inadequate response to NSAIDs: primary analysis of phase 3 trial. Atlanta, Georgia, USA: ACR/ARP Annual Meeting, 2019.

87 Siebert S, Millar NL, McInnes IB. Why did IL-23p19 inhibition fail in as: a tale of tissues, trials or translation? Ann Rheum Dis 2019;78:1015-8.

88 Kristensen LE, Lie E, Jacobsson LTH, et al. Effectiveness and feasibility associated with switching to a second or third TNF inhibitor in patients with psoriatic arthritis: a cohort study from southern Sweden. J Rheumatol 2016;43:81-7.

89 Mease PJ, Gottlieb AB, van der Heijde D, et al. Efficacy and safety of abatacept, a T-cell modulator, in a randomised, double-blind, placebo-controlled, phase III study in psoriatic arthritis. Ann Rheum Dis 2017;76:1550-8.

90 Moverley A, Coates L, Marzo-Ortega H, et al. A feasibility study for a randomised controlled trial of treatment withdrawal in psoriatic arthritis (removal of treatment for patients in remission in psoriatic arthritis (retreat (F)). Clin Rheumatol 2015;34:1407-12.

91 Cantini F, Niccoli L, Nannini C, et al. Frequency and duration of clinical remission in patients with peripheral psoriatic arthritis requiring second-line drugs. Rheumatology 2008;47:872-6.

92 Araujo EG, Finzel S, Englbrecht $M$, et al. High incidence of disease recurrence after discontinuation of disease-modifying antirheumatic drug treatment in patients with psoriatic arthritis in remission. Ann Rheum Dis 2015;74:655-60.

93 Chimenti MS, Esposito M, Giunta A, et al. Remission of psoriatic arthritis after etanercept discontinuation: analysis of patients' clinical characteristics leading to disease relapse. Int J Immunopathol Pharmacol 2013;26:833-8.

94 Janta I, Martínez-Estupiñán L, Valor L, et al. Comparison between full and tapered dosages of biologic therapies in psoriatic arthritis patients: clinical and ultrasound assessment. Clin Rheumatol 2015;34:935-42.

95 Mease $P$. Is reduction or discontinuation of therapy an acceptable possibility in psoriatic arthritis? Clin Exp Rheumatol 2013:31:S59-62. 